\title{
The Exploration of Low Cost Micro Film Creation in the Hot Background of Micro Film in Colleges and Universities
}

\author{
Jing Zhang and Shuai Yuan \\ City college of Wuhan university of science and technology
}

Keywords: Colleges and universities; Micro film creation; Low cost

\begin{abstract}
The purpose of this paper is to analyze the reasons for the popularity of micro film creation in colleges and universities, and provide the ideas and ways for college students to reduce the cost of micro film production by using favorable resources. Tell college students by using advance publicity, to form a team, to borrow business site, the use of school resources, the use of alternative equipment and method to solve the problem of shortage of funds, such as return achieved on the premise of not reduce quality, achieve the goal of low cost to complete micro films. The article is based on the practical exploration of the premise of the experience, has the higher innovation significance and the promotion value.
\end{abstract}

\section{Introduction}

In recent years, the film as a new film and television art form, has become popular in popular culture, and various social groups, cultural departments and relevant enterprises are also pushing rings to wave and launched a variety of purposes "micro movie" series, to make "micro movie" on social groups more and more, make the micro films like bamboo shoots after raining, and flourish everywhere. At present, the group that creates micro films has the most college students. According to statistics, in the near future the script of "2012 international students micro film festival" activities, to participate in competition of 1215 films, involved in all the provinces, more than 100 universities (branch) to more than 50 stations and more than 40, film and television companies took part in the "micro movie" series, including college students work for more than $90 \%$.Therefore, the proportion of college students in the micro film competition is high.

\section{The Cause of the Craze of Micro Film Creation in Colleges and Universities}

\section{Low Cost, Small Scale, Short Period and Easy Operation}

Although many colleges do not set up the micro film class professional, but some of the arts, such as video, animation, visual communication, advertising and other type of professional, many courses and micro movie creation of the necessary knowledge or skills are concerned, so it is easy to cause college students writing interest and enthusiasm.

Unlike cinema film high cost high investment, the film because of low cost, small size, short cycle, easy to operate, the load on creative staff and production personnel, has become more and more the favour of professional or non-professional, especially of film and television or advertising the direction of the university students, have certain professional knowledge, students have the same interest as a team partner, once can prepare to a corresponding device and a small amount of money, a micro movie works can be carried out on., especially in recent years, video equipment and affordable, make equipment expensive problems are addressed in funding, for college students creative micro film practice solves the problem of funding is difficult to prepare.

\section{Micro-Film Creation can Promote the Cultivation of Students' Various Abilities}

The creation of micro films is extremely beneficial to the cultivation of students' various abilities, which is also an important reason for the enthusiastic pursuit of college students. The practice of micro film creation can improve students' abilities in many aspects, mainly reflected in the following aspects: 


\section{It is Conducive to the Cultivation of Comprehensive Practical Ability}

Although the time is short and the quality is not high, some key production processes are similar. Such as prophase planning, script writing, especially design, recruit and acting, scenario planning, filming, dubbing, post-production, creative staff to participate in every link or the point, through the practice of the film, the production process, make the student to the micro film production each link of the specific production requirements have specific fully understand and grasp, greatly improve the comprehensive practical ability.

For example, in the shooting process, how to set the camera's position, Angle and view, how to prevent the camera from wearing help, and how to control the distance and distance control of the recording. The actors walk and shoot angles, the actors' performance and the rhythm of the performance control, how to coordinate the multiple cameras.

And as in post-production, how the lens set, how to form a logical relationship between lens, the light color how to coordinate between the lens and the practice process will give students valuable experience.

Although the students learning in the professional study some related courses or knowledge, but involves the operation of many skills are need to fumble, the teaching of theoretical knowledge into practice, into practical knowledge, to absorb and digest knowledge really. At the same time, students have gained a lot of practical skills and personal experience through the comprehensive practice of creating micro films, so as to lay a solid foundation for entering the social work force after employment.

\section{It is Beneficial to Cultivate Students' Teamwork Spirit}

The creation of micro films is carried out by the team. Each member has a different division of labor. Each member has to work together to complete the production of a micro film together. In this process of long-term cooperation, they can exercise their team spirit and tacit understanding well.

In the process of making a micro film, there are various roles such as director, photographer, actor and field recording. Student teams and professional studio is different, because most is a temporary form, not the economy or industry guild regulations, verbal agreement is limited to only a few specifications, everybody all by consciously abide by, once the classmate don't obey the arrangement is coming into its own, and no way to enforce. Therefore, in this situation, it is more necessary to cultivate the team spirit. Each member should give sincere effort and cooperate with each other to get things done together.

As a micro film production team in the process of micro film, one of the actors like always selfcentered, don't work with someone else, gap time don't want to do some other work; There is also a girl, who needs her later dubbing, which is not actively cooperating, so that the whole team can not go down in this link, which can delay the production progress of the whole team. Although the two classmates later finished their task, but due to their lack of teamwork behavior disgusted by other members, so in the creation of a micro film, they did not invite them to attend. At the same time, because there is the case, to make more to realize the importance of members cooperate with other students, so they promote the other members of the team cooperation spirit, everyone more proactive to voluntarily pay.

Micro films is a combination of creation and practice of comprehensive practice process, through the marketization of the team concept of effective teachers guide, can be set up to work and team cooperation mode as the core of market, to make the students through the practice of the type of this kind of project, can be closely connected with industry market, to lay a good foundation for later obtain employment and professional development.

\section{Promote Students' Ability to Actively Solve Problems}

Students during the college, because of the influence of the exam-oriented education, many students get into the habit of passive learning, they think that as long as study hard in class, complete assigned by the teacher various assignments, to the learning objectives, and rarely take the initiative to go to thinking outside the course knowledge. If students consciously and actively participate in projects such as micro film creation practice, through the completion of the entire 
project, will greatly expand their thinking ability and cultivate their ability to take the initiative to solve various problems.

In addition to the benefits of these, micro films also benefit the students form their own artistic creation mode, and by participating in various design competition or the spread of network platform, show talent, attract the attention of relevant enterprises, expand the good jobs.

\section{College Students can Reduce the Production Cost of Micro Films by Using Favorable Resources}

Although compared with the big cinema film, micro film in all aspects of the investment are small, but the aspects such as personnel, equipment, ground rent or has certain spending, as college students of economic cannot provide for oneself, also be difficult if not clever to deal with.

Produced in the process of the micro film shooting, in addition to the script, a shooting, according to the process need detailed plan, planning schemes such as preparatory work, also need to staff in the process of filming, sites, equipment, props and so on, these are likely to involve funding problems. So how can the college students reduce the cost of campus micro films?

\section{Use the Early Publicity to Expand the Influence}

Some micro film teams spend a lot of time on publicity and preparation in the early days, such as putting up posters in various schools. Strive for professional teachers and counselors to promote in each class; Members of the micro film team appear and encourage everyone to participate. The team set up a special QQ group to absorb students and teachers who are interested in it. Through chatting and discussion in QQ group, we can gain an in-depth understanding and participate actively. Use extracurricular or weekend time to organize the activities of public recruitment in the field, attract attention and so on.

The use of the early publicity to expand the influence, can be in the micro film officially began to operate, to obtain various aspects of support, is also potential to reduce the cost of a way.

\section{Set up Production Team}

College team to shoot the film, directed by fellow college students, launched by creative staff, general subject basic reflect is related the story of the college students, as a creative staff generally has two important post of director and is responsible for photography, but other include actors, late stage management, makeup artist, editor, temporary form according to need. College students in the campus, teams need to do a good job in publicity work, through the school BBS, billboards, students QQ group and class instructor propaganda and widely recruit, encourage everyone to take an active part in, the team try to recruit college students, provides students with both a good practice opportunity, but also reduces the personnel expenses.

\section{Use the Commercial Site for Favorable Support}

University campus as a student school and living place for a long time, site type, more abundant, clean backgrounds, unfavorable goof, micro movie filming on the university students provides a good place. In campus on micro films, natural to make full use of the campus within various scenarios, such as their playground, classrooms, dormitories, library, campus landscape areas, corridor and so on, these after consultation with the school relevant departments are not need to cost. But there are a lot of micro film plot will inevitably involve the social scene, such as restaurants, night market, shops, milk tea shop, even in these places to deduce the plot, finally comes to the business environment will be after the boss agreed to shooting, need team communicate well with his boss.

Experienced team don't think this kind of communication is not only a kind of burden and helpless, will negotiate with some store owners, cooperation on the basis of ads, to enlarge the influence of the shop around the campus, bringing advertising effect and communicate smoothly, not only can get smoothly cooperate to photograph the business place, at the same time also can get some funds to support.

\section{Strive for the Support of Professional Teachers and Relevant Departments}

In the preparation stage of the team, it is better to get the support of professional teachers and some departments. 
The professional teacher can not only carry on the relevant guidance of the professional technical aspect, but also can use the position and the network relations to coordinate with the concerned department, solves some administrative formalities the question.

The department of science and technology has the responsibility to support students' work, and has certain activity funds. If properly communicated, it can effectively help micro film team's shooting work in all aspects.

The propaganda department of the school has the function of promoting campus culture, and there are some equipment needed for publicity work, which can be borrowed through relevant procedures to save the expenses of the micro film team. And after completion of the micro film production, also can get the support of the propaganda department, the propaganda activities on campus and off, screening, submitted all kinds of competition, such as organization campus for the school project bonus, etc., can be in terms of publishing propaganda to the micro movie team to support.

\section{Replace Professional Equipment with Existing Articles and Complete the Special Effects of Quality}

In the process of making micro films, there will be many problems such as professional equipment and special props, which will promote the team members to think and solve problems together. For example, because most of the equipment that students raise is relatively simple, in the process of shooting, it will be difficult for the equipment to achieve certain effects.

In two characters, for example, facing the camera footage of walking and talking, to shoot a oneway long, photographer need to keep the camera steady state under back edge, this lens is commonly used in the professional camera crew will have corresponding orbit device, but the student team can't have. The students can make use of dry land slide to photograph: by photographer stood on the skateboard handheld camera fixed position, others beside drag board, after can make so need lens effect.

Shakes the long boom of the professional machine, for aerial camera, can take advantage of the electronic space model plane, and tied the camera on the model plane, control plane Angle, Angle and shake and all other pictures, can greatly enrich the lens type.

The costumes of the actors are usually collected by the students, and some special costumes that are needed for the plot can be used to rent the costumes of the campus clothing rental stores.

There are some other props, late edit many similar problems, such as the difficulties come only in the process of concrete practice, must solve and unavoidable, greatly exercise the ability to solve the problem. At the same time, through the process of collective creation, people learn from each other, and gather some valuable practical experience, which will help them in their social work after graduation.

Take Advantage of the Completed Works to Participate in Various Competitions to Achieve the After-effect Return

As emerging, film and television art form, at the beginning of the film creation will take into account the audience's feelings, future will accept aesthetic imagery, and the latest technology industry, therefore the micro film has inherent commercial. The micro film team should be good at grasping the market demand, making full use of various competitions and other means to display their talents.

Therefore, in the early stage of micro film creation, it is necessary to make targeted production. After the work is completed, we will participate in various competitions. The display of these works is also a demonstration of the students' talents, providing a platform for their employment. At present, the society to form various kinds of micro film series, on the one hand, for the micro movie creators create a broad platform for the display, at the same time, on the other hand, many industries also micro movie talented person demand, are also seeking suitable talents through these platforms.

\section{Conclusion}

Micro movie this new type of film and television art form, has showed a strong momentum of development, with one of the media industry of the future development and future, bring a lot of 
micro film creation talented person good employment opportunities. As college students, colleges and universities should make full use of the various advantageous resources, micro films under the condition of low cost, is not only the actual practice, good to his college career at the same time a meaningful experiences, give life add a beautiful memory.

\section{References}

[1] Lu Bin/Zheng Yu-ming/Niu Xingzhen, China animation industry development report (2011), social science literature publishing house, May 2011.

[2] Shangdan Dan/Liu Zhangli, "the current situation and development of micro films", "the years of youth", 16, 2012.

[3] Li Ruojun, Li Jing. Evaluation and effect of advertising entertainment [J]. Eastern yue. 2012,33 (4) : $178 \sim 179$.

[4] baidu encyclopedia. Micro movie marketing [Online] : http://ba ike.baidu.com/view/7050326.htm

[5] Xue Ming. Analysis of consumer impulse buying behavior and marketing countermeasures [J]. Enterprise guide.2014(11): 113.

[6] Xindong. Video marketing boom [J]. Business guide.2015(5).

[7] Zhang Ni. Transmission analysis of micro films [D]. Hubei university, 2013.

[8] Yin Cui. Research on the development of Chinese films in the new media era [D]. Zhengzhou

[9] Yin Cui. Research on the development of Chinese films in the new media era [D]. Zhengzhou university, 2016.

[10]Hou Guangming. On the arrival and development path of China's micro film era [J]. Contemporary film.2013(11).

\section{Author Information}

Jing Zhang male date of birth :1968.4), female, wuhan city, hubei province, lecturer, master.Art department of city college of wuhan university of science and technology, research direction: animation.No.8, no.24, steel flower south garden, qingshan district, wuhan city, hubei province, $430080,13396070713$.

Shuai Yuan gender: male date of birth :1985.5 native place: wuhan, hubei.

Unit: wuhan university of science and technology city college art department research direction: animation title: lecturer. 